\title{
EVALUATION OF THE EARLY PROGNOSTIC VALUE OF NEUTROPHIL-LYMPHOCYTE RATIO (NLR) AND PLATELET-LYMPHOCYTE RATIO (PLR) IN SNAKEBITE POISONED PATIENTS
}

\author{
Eglal H. Elawady ${ }^{*}$ and Hany M. Tawfik ${ }^{* *}$ \\ Forensic Medicine \& Clinical Toxicology Department ${ }^{*}$ and Poison Control Center** \\ Faculty of Medicine- Ain Shams University
}

\begin{abstract}
Neutrophil-lymphocyte ratio (NLR) and platelet-lymphocyte ratio (PLR) have recently gained popularity as simple, inexpensive, and highly accurate inflammatory markers and they have been suggested as useful predictors for clinical prognosis in critically ill patients in various medical conditions. This study aimed to assess the usefulness of NLR and PLR in predicting the severity of clinical profile and outcome in patients with snake poisoning. Methods: a prospective study from January to August 2016 and a retrospective one from January to December 2015 were conducted on all snake envenomated patients admitted to Poison Control Center of Ain Shams University Hospitals. On admission, complete medical history, physical examination and biochemical laboratory investigations including complete blood count (CBC) and international normalized ratio (INR), were recorded. NLR and PLR were calculated from the differential total leukocyte count (TLC). Outcome data as; intensive care unit (ICU) and hospital stay time, number of anti-venom (NAV) ampoules needed, occurrence of complications and death, were also documented. The patients were classified in to three main groups, according to the degree of severity; Group II (mild grade); Group III (moderate grade) and Group IV (severe grade). In addition to, Group I (control group). Results: 50 patients, 46 males (92\%), with mean age $(31.54 \pm 11.97$ years) met inclusion criteria. The frequency of bites in the lower limb was significantly higher than those in the upper limb in all patient groups. There was significant leukocytosis, neutophilia and higher LNR in group III and group IV as compared to group I and group II. Significant lymphocytopenia and thrombocytopenia was evident in group III and group IV as compared to group I and also in group IV compared to group II. INR was statistically higher in group IV in comparison with the other groups. There was significant correlation of NLR level with INR, platelet count, PLR, NAV, ICU stay time and hospital stay time. While, PLR showed non-significant difference between the studied groups as well as non-significant correlation with the outcome parameters. The mortality rate of the study was (2\%). Conclusion: High levels of on admission NLR were associated with worse clinical profile and poorer outcome. This was not evident with PLR. NLR was found to function as a new easily calculated readily available biomarker that successfully predicts the prognosis of clinical severity and outcome in snake poisoned patients.
\end{abstract}

Key words: Snake, Poisoning, NLR, PLR. 


\section{INTRODUCTION}

Snake envenomation is one of the major medical and public health problems in the world. Annually, there is 1 to 2 million cases of snake envenomation and up to 100,000 deaths worldwide (Maduwage et al., 2014). There are 3,000 different species of snakes, and about 450 are found to be dangerous for humans universally (Saravu et al., 2012). Two of these poisonous species are famous in Egypt; the family Viberidae (vipers) and the family Elabidae (Egyptian copra: Naja Haje) (Filippi and Petretto, 2013; Ibrahim and El-Kady, 2016).

Snake venom is a complex mixture of enzymatic and non-enzymatic protein and peptide toxins. Most of which of them, can target the vital systems such as nervous, muscular, haemostatic and circulatory systems of the prey or human victims producing diverse effects (Sharma et al., 2015).

The clinical features are manifested as; severe local (at bite site) pain, progressive edema, erythema, ecchymosis, bleeding, blisters, bullae, necrosis and gangrene, as well as systemic disorders such as coagulation disturbances, disseminated intravascular coagulation, hemorrhage of vital organs, hypotension and shock after Viberidae bite (Sunithaa et al., 2011; Dadpour et al., 2012; David et al., 2014; Berling and Isbister, 2015). While, minimal local changes together with neurotoxic effects starting with ptosis, ophthalmoplegia , glossopharyngeal paralysis and proceeding to descending flaccid paralysis of skeletal muscles and respiratory failure are evident after Elapidae bite (Ahmed et al., 2008; AlQuraishy et al., 2014). Both envenomations can end fatally with rhabdomyolysis, acute renal failure, shock, cardiac and respiratory arrest (Mishal et al., 2015).

Treatment for poisonous snakebite is divided into supportive care and antivenom administration. However, there is no standardized guideline on antivenom administration and depending solely on severity of symptoms at presentation for clinical assessment is not reliable. It is very difficult to predict the expansion of localized and systematic symptoms. In some cases, generalized symptoms develop in the absence of localized symptoms. It is believed that when the initial dose is not adequate and/or delayed, it might worsen the morbidity and mortality rates (Kang et al., 2016).

Bedside investigations would be ideal, but international normalized ratio (INR) and whole blood clotting tests have been shown to be unreliable in many settings especially in critically ill patients with multi-organ failure as a result of snake bite (Khin et al., 2012; Isbister et al., 2015). Thus, it is important that the health care providers should be able to identify patients with snakebites at high risk of fatal complications early enough so as to be able to ensure optimum and timely management.

The neutrophil-lymphocyte ratio (NLR) and the platelet-lymphocyte ratio (PLR) measured in peripheral blood as part of routine complete blood count (CBC), have recently gained recognition as practical simple inexpensive tests. Both ratios indicate increased local and systemic inflammatory response (Duyar et al., 2016). They can provide valuable information for the diagnosis and prognosis of various critical illnesses (Alan et al., 2015). 
The aim of this study is to evaluate the effectiveness of measuring on admission pre-treatment NLR and PLR levels in predicting the severity of the clinical course and outcome of snake poisoned patients.

\section{PATIENTS \& METHODS}

A prospective observational study from January 2016 to August 2016 and a retrospective one from January 2015 to December 2015 were conducted on all snake envenomated patients, admitted to the Poison Control Center of Ain Shams University Hospitals (PCC-ASUH). The diagnosis of snake envenomation was based on history of exposure to snake bite and the presence of characteristic clinical symptoms and signs. The study exclusion criteria applied included; referral from other hospital with initial treatment and/or more than 48 hours after being bitten, patients with history of hematologic, liver, renal, pulmonary, cardiac, neurological, endocrinal or immunological diseases, in addition to, patients with diabetes, allergic conditions or infectious diseases, pregnant females and those with absence of a measurable serum CBC in the retrospective study. An informed written consent was taken from the patient or his/her legal guardian in addition to head of PCC and Ethical Committee approval.

\section{Methods:}

The medical records of all snake envenomatd patients in 2015 were reviewed for the retrospective study. As for the prospective study in 2016; the patients with snake envenomation were subjected to initial on admission complete medical history including: age, gender, site of bite and delay time (time interval from envenomation to arrival to hospital), physical examination including: local examination of bite site: number and site of fang marks, pain, edema, ecchymosis, blistering, petichae, local (bleeding and infection) and regional enlarged tender lymph nodes, together with general manifestations, vital data, complete systemic examination with stress on haematological examination: bleeding gums, conjunctival congestion, epistaxis, hematemesis, hematuria, hematochezia, signs and symptoms of internal bleeding. Biochemical laboratory investigations on admission especially haematological tests: complete blood count (CBC) including: total leukocyte count (TLC), neutophil, lymphocyte and platelet counts, using Coulter Counter ModelM450 [Coulter Electronics Ltd, Australia]. International normalized ratio (INR): using BE-Behnk Elektronik Coagulator. NLR and PLR were calculated using absolute neutophil, lymphocyte and platelet counts retrieved from the differential TLC (Venkatraghavan et al., 2015).

Outcome data including: duration of hospital stay, duration of intensive care unit (ICU) stay, number of antivenom (NAV) ampoules needed, occurrence of complications as; spontaneous bleeding, ecchymosis, petichae, gangrene, necrosis, hematuria, rhabdomyolysis, disseminated intravascular coagulopathy (DIC), renal faiure, hepatic failure, sepsis, limb disability, compartment syndrome, amputation, paralysis and mortality rate were recorded.

\section{The Groups:}

Ten apparently healthy volunteers of matched age and gender were included as a control group (Group I). 
The clinical assessment of patients was sorted according to a questionnaire sheet and the patients were classified into three main groups, based on the degree of local and systemic severity of envenomation; Group II (mild grade) including moderate pain, local manifestations confined to bite site (0$15 \mathrm{~cm})$ and no systemic signs or symptoms, Group III (moderate grade) including severe pain, progression of swelling (15-30 cm), erythema, or ecchymosis beyond bite site, non-life threatening signs or symptoms (sweating, weakness, nausea/vomiting, mild hypotension, perioral paresthesias, thrombocytopenia, anemia) and without significant bleeding, Group IV (severe grade) including severe pain, rapid swelling $(>30 \mathrm{~cm})$, erythema, or ecchymosis involving the entire body part, severe systemic signs or symptoms and spontaneous bleeding (kiran and Senthilnathan et al., 2003; Ray et al., 2011).

All patients received standard medical treatment. This followed an approved standard protocol, which was dictated by the patient's clinical condition. The protocol included hospital admission. Patients with no systemic manifestations were sent to the intermediate care unit for observation. Patients with moderate and severe envenomation were transferred to the ICU. Anti-venom, intubation and mechanical ventilation, heamodialysis, fasciotomy or other surgical intervention, blood, fresh frozen plasma, platelets concentrate transfusion, inotropic and supportive drugs were given if indicated (Mishal et al., 2015).

Statistical Analysis: The results were statistically analyzed using the SPSS software, version 17 (SPSS, Inc.,
Chicago, IL).Quantitative data are described as Mean \pm standard deviation (SD). ANOVA one way statistical analysis was used to compare between the groups. Discrete variables were analyzed using Chi-square test $\left(\chi^{2}\right)$. The Pearson's correlation coefficient was used to assess the relationship between laboratory values and clinical severity. $\mathrm{P}$ values $<0.05$ were considered statistically significant (Taylor, 1990).

\section{RESULTS}

A total of 50 patients, 26 patients in the year 2015 and 24 patients in the months from (January to August) of the year 2016, met inclusion criteria. The average age was $(31.54 \pm 11.97$ years), while the average delay time was $(12.74 \pm 3.96$ hours) with nonsignificant difference between mild, moderate and severe groups as compared with the control group or with each other (Table1). Male predominance (46 patients; 92\%) was evident with non-significant difference between the three patient groups (mild, moderate and severe) (Table2). The species type of the venomous snakes could not be exactly identified. All patients were heamotoxic (heamorrhagic clinical picture). One case $(2 \%)$ died as a result of multiple organ failure (MOF); renal and hepatic failure in 2015 . There were only two patients with paralytic clinical picture and they were excluded from the study due to referral and delay time more than 3 days.

Table (2): also shows that there was significant increase in the incidence of snake bite in the lower limb compared to the upper limb bite site in the mild, moderate and severe groups of snake poisoned patients with 
non-significant difference between the three groups. None of the patients presented with bite site in the trunk, head or neck.

Table (3): shows that there was significant increase of TLC, neutrophil count and NLR in group III (moderate grade) and group IV (severe grade) in comparison to group I (control group) and group II (mild grade). While, there was significant decrease of lymphocyte and platelet counts in group III and group IV in comparison to the control group and significant decrease in group IV compared to group II. There was non-significant difference in the level of PLR between the studied groups. The severe grade (group IV) showed significant increase of INR level in comparison to the groups I, II and III.

Table (4): shows that there was significant increase of NAV and hospital stay time in group IV (severe grade) in comparison to group II (mild grade) and group III (moderate grade). Also there was significant increase of ICU stay time in group IV (severe grade) in comparison to group II (mild grade). While there was non-significant difference between the mild and moderate groups regarding NAV, ICU and hospital stay time.

Table (5): shows the proportions of severe complications within group IV (severe grade) which included: ecchymosis (42.9\%), compartment syndrome that necessitated fasciotomy (3.6\%), psoas abscess (3.6\%), gangrene $(7.1 \%)$, renal failure necessitating heamodialysis $(7.1 \%)$, hepatic failure (3.6\%), hematuria $(17.9 \%)$ and spontaneous bleeding (epistaxis, bleeding gums, hematemesis) (10.7\%).

Table (6): shows that there was significant positive correlation of NLR level with INR level, NAV, ICU stay time and hospital stay time and significant negative correlation with platelet count. On the other hand there was non-significant correlation of PLR level with INR, NAV, ICU and hospital stay time. While there was highly significant positive correlation between PLR level and platelet count.

Table (1): ANOVA one way statistical analysis of age and delay time among snake poisoned patients; group II (mild grade), group III (moderate grade), group IV (severe grade) and the control group (group I).

\begin{tabular}{|l|c|c|c|c|c|}
\hline & $\begin{array}{c}\text { Group I } \\
(\mathbf{N O = 1 0}) \\
\mathbf{M} \pm \text { SD }\end{array}$ & $\begin{array}{c}\text { Group II } \\
(\mathbf{N O = 1 2}) \\
\mathbf{M} \pm \text { SD }\end{array}$ & $\begin{array}{c}\text { Group III } \\
(\mathbf{N O = 1 0}) \\
\mathbf{M} \pm \text { SD }\end{array}$ & $\begin{array}{c}\text { Group IV } \\
(\mathbf{N O = 2 8}) \\
\mathbf{M} \pm \text { SD }\end{array}$ & Fc \\
\hline Age (years) & $28.8 \pm 6.12$ & $25.7 \pm 6.87$ & $29.4 \pm 9.27$ & $34.7 \pm 11.58$ & 1.24 \\
\hline Delay time (hours) & - & $12 \pm 4.07$ & $17.8 \pm 5.82$ & $11.25 \pm 3.08$ & 2.27 \\
\hline
\end{tabular}

$\mathrm{M} \pm$ SD: mean \pm standard deviation. NO: Number. Fc: calculated variance ratio. Ft: tabulated variance ratio $=3.43$. 
Table (2): Chi square test $(\chi 2)$ comparing gender and bite site among snake poisoned patients; group II (mild grade), group III (moderate grade) and group IV (severe grade).

\begin{tabular}{|l|c|c|c|c|}
\hline & $\begin{array}{c}\text { Group II } \\
\text { (NO=12) }\end{array}$ & $\begin{array}{c}\text { Group III } \\
\text { (NO=10) }\end{array}$ & $\begin{array}{c}\text { Group IV } \\
\text { (NO=28) }\end{array}$ & P2 \\
\hline $\begin{array}{l}\text { Gender } \\
\text { Male/female ratio }\end{array}$ & $12 / 0$ & $9 / 1$ & $25 / 3$ & \\
Male percentage & $(100 \%)$ & $(90 \%)$ & $(89.3 \%)$ & $>0.05$ \\
P1 & $<0.001$ & $<0.001$ & $<0.001$ & \\
\hline Bite site & & & & \\
Lower limb & $9(75 \%)$ & $9(90 \%)$ & $22(78.6 \%)$ & $>0.05$ \\
Upper limb & $3(25 \%)$ & $1(10 \%)$ & $6(21.4 \%)$ & $>0.05$ \\
Trunk & $0(0 \%)$ & $0(0 \%)$ & $0(0 \%)$ & - \\
Head and neck & $0(0 \%)$ & $0(0 \%)$ & $0(0 \%)$ & - \\
P1 & $<0.05$ & $<0.001$ & $<0.001$ & \\
\hline
\end{tabular}

NO: Number. $P>0.05$ : non-significant difference. $P<0.05$ : significant difference. P<0.001: highly significant difference. $P 1$ : comparison within each group.

P2: comparison between the three groups.

Table (3): ANOVA one way statistical analysis comparing on admission total leukocyte count (TLC), lymphocyte count, neutrophil count, neutrophillymphocyte ratio (NLR), platelet count, platelet-lymphocyte ratio (PLR) and international normalized ratio (INR) among snake poisoned patients; group II (mild grade), group III (moderate grade), group IV (severe grade) and the control group (group I).

\begin{tabular}{|c|c|c|c|c|c|}
\hline $\begin{array}{l}\text { Groups } \\
\text { Parameters }\end{array}$ & $\begin{array}{c}\text { Group I } \\
(\mathrm{NO}=10) \\
\mathrm{M} \pm \mathrm{SD}\end{array}$ & $\begin{array}{c}\text { Group II } \\
(\mathrm{NO}=12) \\
\mathrm{M} \pm \mathrm{SD}\end{array}$ & $\begin{array}{c}\text { Group III } \\
(\mathrm{NO}=10) \\
\mathrm{M} \pm \mathrm{SD}\end{array}$ & $\begin{array}{c}\text { Group IV } \\
(\mathrm{NO}=28) \\
\mathrm{M} \pm \mathrm{SD}\end{array}$ & Fc \\
\hline $\begin{array}{l}\text { TLC } \\
\left(\mathbf{x 1 0} / \mathbf{m m}^{3}\right)\end{array}$ & $5.69 \pm 1.00$ & $6.25 \pm 2.22$ & $10.53 \pm 3.68^{* \Delta}$ & $11.24 \pm 4.24^{* \Delta}$ & 10.00 \\
\hline $\begin{array}{l}\text { Lymphocyte } \\
\left(\mathbf{x 1 0}^{3} / \mathbf{m m}^{3}\right)\end{array}$ & $1.95 \pm 0.48$ & $1.62 \pm 0.58$ & $1.28 \pm 0.43^{*}$ & $1.20 \pm 0.51^{* \Delta}$ & 6.12 \\
\hline $\begin{array}{l}\text { Neutrophil } \\
\left(\mathbf{x 1 0}^{3} / \mathrm{mm}^{3}\right)\end{array}$ & $3.34 \pm 0.65$ & $4.2 \pm 2.08$ & $8.82 \pm 3.39^{*} \Delta$ & $9.63 \pm 3.95^{* \Delta}$ & 14.48 \\
\hline LNR & $1.74 \pm 0.48$ & $2.9 \pm 1.75$ & $7.41 \pm 3.52^{* \Delta}$ & $9.24 \pm 4.47^{* \Delta}$ & 16.28 \\
\hline $\begin{array}{l}\text { Platelet } \\
\left(\mathbf{x}^{3} 0^{3} / \mathbf{m m}^{3}\right)\end{array}$ & $281.5 \pm 61.87$ & $231.08 \pm 33.54$ & $192.8 \pm 84.02^{*}$ & $169 \pm 79.12^{* \Delta}$ & 6.97 \\
\hline PLR & $151.28 \pm 51.17$ & $161.66 \pm 67.74$ & $162.15 \pm 87.7$ & $164.87 \pm 89.79$ & 0.06 \\
\hline INR & $0.99 \pm 0.09$ & $1.35 \pm 0.37$ & $3.06 \pm 1.43$ & $10.42 \pm 6.57^{* \Delta \#}$ & 17.99 \\
\hline
\end{tabular}

M \pm SD: mean \pm standard deviation. NO: Number. Fc: calculated variance ratio. Ft: tabulated variance ratio=3.43. *: significant difference as compared to (group I) $\mathbf{P}<\mathbf{0 . 0 5}$.

$\Delta$ : significant difference as compared to (group II) $\mathbf{P}<0.05$. \#: significant difference as compared to (group III) $P<0.05$. 
Table (4): ANOVA one way statistical analysis of number of anti-venom vials (NAV) needed, intensive care unit (ICU) stay time and hospital stay time among snake poisoned patients; group II (mild grade), group III (moderate grade) and group IV (severe grade).

\begin{tabular}{|c|c|c|c|c|}
\hline $\mathrm{N}_{\text {Parameters }}^{\text {Groups }}$ & $\begin{array}{c}\text { Group II } \\
(\mathrm{NO}=12) \\
\mathrm{M} \pm \mathrm{SD}\end{array}$ & $\begin{array}{c}\text { Group III } \\
(\mathrm{NO}=10) \\
\mathrm{M} \pm \mathrm{SD}\end{array}$ & $\begin{array}{c}\text { Group IV } \\
(\mathrm{NO}=28) \\
\mathrm{M} \pm \mathrm{SD}\end{array}$ & Fc \\
\hline NAV & $6.08 \pm 2.28$ & $13.8 \pm 4.83$ & $24.85 \pm 11.8^{\Delta \#}$ & 8.34 \\
\hline ICU stay time (days) & $0.75 \pm 0.62$ & $1.4 \pm 1.07$ & $3.07 \pm 2.4^{\Delta}$ & 5.04 \\
\hline Hospital stay time (days) & $1.91 \pm 1.24$ & $3.2 \pm 2.14$ & $5.46 \pm 3.17^{\Delta \#}$ & 9.21 \\
\hline
\end{tabular}

M \pm SD: mean \pm standard deviation. NO: Number. Fc: calculated variance ratio.

Ft: tabulated variance ratio $=3.43 . \Delta$ : significant difference as compared to $($ group II) $\mathbf{P}<0.05$ : \#: significant difference as compared to (group III) $\mathbf{P}<0.05$.

Table (5): Percentages of complications in group IV (severe grade; $\mathrm{NO}=28$ ) of snake poisoned patients.

\begin{tabular}{|l|l|}
\hline & NO (\%) \\
\hline Ecchymosis & $12(42.9 \%)$ \\
\hline Compartment syndrome \&fasciotomy & $1(3.6 \%)$ \\
\hline Psoas abscess & $1(3.6 \%)$ \\
\hline Gangrene & $2(7.1 \%)$ \\
\hline Renal failure & $2(7.1 \%)$ \\
\hline Hepatic failure & $1(3.6 \%)$ \\
\hline Hematuria & $5(17.9 \%)$ \\
\hline $\begin{array}{l}\text { Spontaneous bleeding } \\
\text { (epistaxis/ bleeding gum/ } \\
\text { hematemesis) }\end{array}$ & $3(10.7 \%)$ \\
\hline
\end{tabular}

\section{NO: Number}

Table (6): Pearson's correlation of neutrophil-lymphocyte ratio (NLR) and plateletlymphocyte ratio (PLR) with international normalized ratio (INR), platelet count, PLR, number of anti-venom vials (NAV) needed, intensive care unit (ICU) stay time and hospital stay time in snake poisoned patients; groups II (mild grade), group III (moderate grade) and group IV (severe grade).

\begin{tabular}{|c|c|c|c|c|c|c|}
\hline 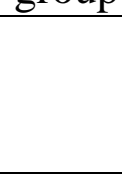 & INR & $\begin{array}{c}\text { Platelet } \\
\text { Count } \\
(\times 103 / \mathrm{mm} 3)\end{array}$ & PLR & NAV & $\begin{array}{c}\text { ICU stay } \\
\text { time } \\
\text { (days) }\end{array}$ & $\begin{array}{c}\text { Hospital } \\
\text { stay time } \\
\text { (days) }\end{array}$ \\
\hline $\begin{array}{l}\text { NLR } \\
\mathbf{r} \\
\mathbf{P}\end{array}$ & $\begin{array}{l}0.280 * \\
<0.05\end{array}$ & $\begin{array}{l}-0.402^{*} \\
<0.05\end{array}$ & $\begin{array}{l}0.348^{*} \\
<0.05\end{array}$ & $\begin{array}{c}0.354 * \\
<0.05\end{array}$ & $\begin{array}{l}0.319^{*} \\
<0.05\end{array}$ & $\begin{array}{l}0.357^{*} \\
<0.05\end{array}$ \\
\hline $\begin{array}{l}\text { PLR } \\
\mathbf{r} \\
\mathbf{P}\end{array}$ & $\begin{array}{l}0.187 \\
>0.05\end{array}$ & $\begin{array}{l}0.446 * * \\
<0.001\end{array}$ & $\begin{array}{l}1 \\
-\end{array}$ & $\begin{array}{r}0.120 \\
>0.05\end{array}$ & $\begin{array}{r}0.140 \\
>0.05\end{array}$ & $\begin{array}{r}0.153 \\
>0.05\end{array}$ \\
\hline
\end{tabular}

"r": correlation coefficient. $P>0.05$ : non-significant correlation.

$* \mathbf{P}<0.05$ : significant

correlation. $* * \mathbf{P}<0.001$ : high significant correlation. 


\section{DISCUSSION}

Throughout the world, snake envenoming remains life-threatening concern (Hifumi et al., 2015). Male gender and lower limb site of bite predomination in this study was similar to the findings of previous studies (Chattopadhyay and Sukul, 2011; Khin et al., 2012; Saravu et al., 2012; Kang et al., 2016). This hazard is related to greater number of outdoor activities and occupational nature of exposure of males compared to their female counterparts (Saravu et al., 2012).

Snake poisoning course may be fulminant and lethal, thus recognition of prompt parameter could reduce the mortality (Khin et al., 2012). Preliminary evidence has suggested that, leukocytes and their subtypes (granulocytes, monocytes and lymphocytes) counts can be used as a marker of inflammation in many diseases (Horne et al., 2005; Duyar et al., 2016). When the differential count of leukocytes is evaluated during the acute inflammatory response to oxidative stress, it is characterized by an increase in neutrophil and monocyte counts and a decline in lymphocyte counts (de Jager et al., 2010; Dundar et al., 2014). In this study there was significant increase of TLC and neutrophil counts and a significant decrease of lymphocyte count in the moderate and severe groups of snake poisoned patients in comparison to the mild and control groups. This is similar to studies by Moreira et al. (2009); Zornetta et al. (2012); Elbey et al. (2015) who reported significant leukocytosis, neutrophilia and lymphocytopenia in patients with snake poisoning. The inflammatory properties of snake toxicity are attributed to its venom composition (Zornetta et al., 2012). In circulatory system, snake venoms not only affect vessel wall, platelet function, clot formation, and clot dissolution, but also target blood cells. Cells of the innate immunity, the white blood cells, are highly sensitive and take part in the venom-induced inflammatory and oxidant response (Sharma et al., 2015). A study by Chacón et al. (2015) reported common inflammatory events following viperidae snake bites envenomation. Significant release of pro-inflammatory mediators as; Interleukin (IL)-6, IL-10, tumor necrosis factor alpha (TNF $\alpha)$ together with surge of reactive oxygen species (ROS) indicating obvious inflammatory and oxidant stress following snake envenoming was noticed by Avila-Agüero et al. (2001); Acikalin and Gokel (2011); Stone et al. (2013); Sharma et al. (2015). In a study by Al Durihim et al. (2010) leukocytosis was an encountered finding in the complete blood count of patients admitted to hospital with snakebite. In another study by Isbister et al. (2016) leukocytosis was evident even before detection of significant coagulopathy and prolonged PTT following snake poisoning. A correlation between snake evenomations and sterile inflammatory syndrome and innate immune response that might contribute to the local and systemic inflammatory events with induction of neutrophil activation is suggested by Zornetta et al. (2012). Elevated neutrophil count starts from the first hour due to demargination of neutrophils from the endothelium, delay of neutrophil apoptosis, and effect of growth factors on stem cells (Akilli et al., 2014). Whereas, lymphocytopenia occurs in response to 
physiological stress-induced margination to the reticulo-endothelial system, redistribution and accelerated apoptosis (Acanfora et al., 2001; Duyar et al., 2016).

The increase of neutrophil and the decrease of lymphocyte counts explain the on admission pre-treatment high levels of neutrophil-lymphocyte ratio (NLR) in this study among the moderate and severe groups of snake envenomated patients. This is in accordance with a study by Elbey et al. (2015). NLR is a recently defined novel inflammatory marker which has emerged as a readily available, valuable and reliable method for follow-up of a number of local and systemic inflammatory diseases (Coşkun et al., 2014; Kawahara et al., 2016). Its prognostic value was proved in non-poisoning settings as; cardiovascular and pulmonary diseases and related co-morbidities detection, as well as in diverse immuneinflammatory diseases (Kaya et al., 2013; Solak et al., 2013; Ataseven et al., 2014; Buyukkaya et al., 2014; Rifaioglu et al., 2014; Duyar et al., 2016). NLR was also shown to be a predictor of survival and response to treatment in various types of malignancies (Walsh et al., 2005; Lee et al., 2012; Yao et al., 2013; Kawahara et al., 2016).

In the current study, there was significant correlation between NLR and the increase of international normalized ratio (INR), number of antivenom (NAV) vials, thrombocytopenia, Platelet-lymphocyte ratio (PLR), hospital stay time and intensive care unit (ICU) stay time. NLR was higher in the severe and complicated cases. This association of on admission pretreatment high NLR with worse outcome indicates the value of NLR as a prognostic factor of snake poisoning. Similarly, Elbey et al. (2015) found that NLR was significantly increased in patients who developed complications and needed a longer hospitalization. Salciccioli et al. (2015) stated that mortality was higher in patients with increased NLR. Although complications occurred in some cases of snake bites in the severe group, only one case died of multiple organ failure (MOF) in this study. Elevated NLR is believed to be associated with increased in-hospital and post-hospital mortality (Balta ${ }^{\text {b }}$ et al., 2013; Venkatraghavan et al., 2015). Akilli et al. (2014) stated that NLR provide an accurate guidance for follow up and therapeutic intervention and can also enlighten the physician to the development of MOF and sepsis, particularly within a few hours after admission in critically ill patients. Another study on 90 ICU patients stated that NLR was more reliable parameter for reflecting the intensity of stress, evaluating and monitoring systemic inflammatory response and predicting short and long mortality (Zahorec, 2001). In poisoning settings associated with oxidative stress, NLR was found to be useful for estimating prognosis and follow up in pesticide and herbicide poisoned patients (Kang et al., 2013; Dundar et al., 2014). Elevated NLR has been shown to be associated with increased TNF $\alpha$ and various interleukins (IL-6, IL-7, IL-8, IL-12, IL-17). These markers (previously mentioned to be involved in snake venom toxicity) are known to be associated with poor outcome in critically ill patients. However, measuring these biomarkers is expensive and is not routinely 
performed. In contrast, NLR is a simple index derived from routine blood tests which might provide equal and valuable information

(Venkatraghavan et al., 2015; Wang et al., 2016). Because it is a ratio, NLR is relatively more stable than individual leukocytic parameters that are easily altered by many simple conditions (eg. dehydration, over hydration, diluted blood specimens, and in vitro blood specimen handling) (Balta ${ }^{\mathbf{a}}$ et al., 2013).

Regarding NAV vials in this study, it was higher in the severe group in comparison to the mild and moderate groups of snake poisoned patients and there was significant positive correlation of NLR level with NAV. When the initial dose is not sufficient, it may result in worse clinical outcomes (Dadpour et al., 2012). It is believed that the total NAV vials administered indicates the worseness of patient's condition and somehow determines the severity of snake bite toxicity (Kang et al., 2016).

As regards INR, its elevation is well known to be one of the manifestations of viper venom induced consumption coagulopathy and haemostatic disturbances (Maduwage et al., 2014). In this study INR was higher in the severe group in comparison to the mild and moderate groups of snake poisoned patients and there was significant positive correlation between NLR and INR levels. Pre-NAV venom concentrations and poorer outcome are found to be correlated with higher INR (Isbister et al., 2015). This strengthens the proposed prognostic value of NLR in snake poisoning of this study.

Besides NLR, platelets are found to be associated with disease activity in patients with inflammatory disease. They play a significant role in inflammation and immunity, besides being major elements of hemostasis (Coşkun et al., 2014). Plateletlymphocyte ratio (PLR) is a new biomarker indicating presence and severity of inflammation (Qin et al., 2016). Like NLR, PLR in peripheral blood is easy, readily available systemic inflammatory response (Bozan et al., 2016). Elevated PLR levels are frequently observed in nonpoisoning conditions as; in various malignancies, cardiac diseases and immune-inflammatory diseases (Kokcu et al., 2014; Sunbul et al., 2014; Koseoglu et al., 2015; Alan et al., 2015; Qin et al., 2016; Bozan et al., 2016) and in poisoning conditions with oxidative stress as in pesticide poisoning where it is associated with bad prognosis and high mortality rate but with lesser efficacy than NLR (Dundar et al., 2014).

In the current study, PLR was elevated in the severely poisoned patients, but this increase was not statistically significant, also there was non-significant correlation of PLR with INR, NAV, ICU and hospital stay time. The explanation could be that the increase in PLR might be relative to lymphocytopenia but non-significant owing to the decreased platelet count characteristic of the nature of snake poisoning. This goes hand in hand with the results in this work where there was significant decrease of platelet count in the severe and moderate groups as compared with the control group. Thrombocytopenia is due to the platelet aggregation activity of the snake venom (Hifumi et al., 2015). The masking effect of thrombocytopenia on PLR was also 
encountered in another poisoning setting with organophosphates toxicity (Dundar et al., 2014).

In Conclusion: Pre-treatment on admission NLR was significantly increased in the moderately and severely snake poisoned patients. Also, there was significant correlation of NLR with poorer outcomes (increased INR, PLR, NAV, ICU stay time and hospital stay time and thrombocytopenia). While, PLR levels showed non-significant difference between groups and there was nonsignificant correlation of PLR with the outcome. It is recommended to use NLR as an early, easily, readily available, low cost and useful parameter to predict severity and direct therapy of snake poisoned patients specially in clinical settings lacking INR and other blood clotting tests. It is suggested to evaluate more the value of PLR in the paralytic type of snake envenoming where the masking effect of thrombocytopenia might be lessened or abolished. Further studies on larger scale to define more the prognostic role of NLR and PLR in snake poisoning are warranted.

\section{REFERENCE}

Acanfora, D.; Gheorghiade, M.; Trojano, L. et al., (2001): Relative lymphocyte count: a prognostic indicator of mortality in elderly patients with congestive heart failure. Am Heart J, 142:167-173.

Acikalin, A. and Gokel, Y. (2011): Serum IL-6, TNFalpha levels in snakebite cases occurring in Southern Turkey. Emergency Med J, 28:208-211.

Ahmed, S.; Ahmed, M.; Nadeem, A. et al., (2008): Emergency treatment of a snake bite: Pearls from literature. J Emerg Trauma Shock, 1(2): 97-105.

Akilli, N.; Yortanli, M.; Mutlu, H. et al., (2014): Prognostic importance of neutrophil-lymphocyte ratio in critically ill patients: short- and long-term outcomes. American Journal of Emergency Medicine, 32: 1476-1480.

Alan a, S.; Tuna, S. and Turkoglu, E. (2015): The relation of neutrophilto-lymphocyte ratio, platelet-tolymphocyte ratio, and mean platelet volume with the presence and severity of Behcet's syndrome. Kaohsiung Journal of Medical Sciences, 31: 626-631.

Al Durihim, H.; Al Hussaini, M.; Bin Salih, S. et al., (2010): Snake bite envenomation: experience at King Abdulaziz Medical City, Riyadh. East Mediterr Health J, 16(4): 438441.

Al-Quraishy, S.; Dkhil, M. and Abdel Moneim, A. (2014): Hepatotoxicity and oxidative stress induced by Naja haje crude venom. J Venom Anim Toxins Incl Trop Dis, 20: 42.

Ataseven, A.; Bilgin, A. and Kurtipek, G. (2014): The importance of neutrophil lymphocyte ratio in patients with psoriasis. Materia Sociomedica, 26: 231.

Avila-Agüero, M.; Paris, M.; Hu, S. et al., (2001): Systemic cytokine response in children bitten by snakes in Costa Rica. Pediatr Emerg Care, 17(6):425-429.

Balta $^{\text {a }, ~ S . ; ~ D e m i r k o l, ~ S . ; ~ H a t i p o g l u, ~}$ M. et al., (2013): Other inflammatory indicators should be kept in mind when assessing red cell distribution width in patients 
with pneumonia. Am J Emerg Med, 31(7): 1144-1145.

Balta $^{\mathrm{b}}$, S.; Demirkol, S.; Unlu, M. et al., (2013): Neutrophil to lymphocyte ratio may be predictor of mortality in all conditions. Br J Cancer, 109(12): 3125-3126.

Berling, I. and Isbister, G.(2015): Hematologic effects and complications of snake envenoming. Transfus Med Rev, 29(2):82-89.

Bozan, N.; Alpayci, M.; Aslan, M. et al., (2016): Mean platelet volume, red cell distribution width, plateletto-lymphocyte and neutrophil-tolymphocyte ratios in patients with ankylosing spondylitis and their relationships with high-frequency hearing thresholds. Eur Arch Otorhinolaryngol, 273(11):36633672.

Buyukkaya, E.; Karakas, M.; Karakas, E. et al., (2014): Correlation of neutrophil to lymphocyte ratio with the presence and severity of metabolic syndrome. Clin Appl Thromb Hemost, 20: 159-163.

Chacón, B.; Gutierrez, H.; Fallas, A. et al., (2015): Bacterial infections associated with Viperidae snakebites: a 14-year experience at the Hospital Nacional de Niños de Costa Rica.9th world congress of the world society for pediatric infectious diseases (WSPID) Rio De Janeiro Brazil November 18-20, 2015.

Chattopadhyay, S. and Sukul, B. (2011): A profile of fatal snake bite cases in the Bankura district of West Bengal. J Forensic Leg Med, 18:18-20.

Coşkun, B.; Öksüz, M.; Ermurat, S. et al., (2014): Neutrophil lymphocyte ratio can be a valuable marker in defining disease activity in patients who have started antitumor necrosis factor (TNF) drugs for ankylosing spondylitis. Eur J Rheumatol, 1: 101-105.

Dadpour, B.; Shafahi, A.; Mostafa, S. et al., (2012): Snakebite prognostic factors: leading factors of weak therapeutic response following snakebite envenomation. APJMT, 1: 27-33.

David, R.; Theakston, G. and Laing G. (2014): Diagnosis of snakebite and the importance of immunological tests in venom research. Toxins, 6: 1667-1695.

de Jager, C.; Vanwijk, P.; Mathoera, R. et al., (2010): Lymphocytopenia and neutrophil-lymphocyte count ratio predict bacteremia better than conventional infection markers in an emergency care unit. Crit Care, 14:R192.

Dundar, Z.; Ergin, M.; Koylu, R. et al., (2014): Neutrophil-lymphocyte ratio in patients with pesticide poisoning.The Journal of Emergency Medicine, 47(3):286293.

Duyar, S.; Solak, Y.; Tekis, D. et al., (2016): Platelet to lymphocyte ratio as a novel prognostic marker in male patients with chronic obstructive pulmonary disease. Int J Respir Pulm Med, 3:043.

Elbey, B.; Baykal, B.; Yazgan, U. et al., (2015): The prognostic value of the neutrophil/lymphocyte ratio in patients with snake bites for clinical outcomes and complications. Saudi Journal of Biological Sciences, http://dx.doi.org/10.1016/j.sjbs.201 5.10.002. 
Filippi, E. and Petretto, M. (2013): Naja haje (Egyptian cobra) diet/ophiophagy. Herpetological Review, 44(1):155-156.

Hifumi, T.; Sakai, A.; Kondo, Y. et al., (2015): Venomous snake bites: clinical diagnosis and treatment. $\mathbf{J}$ Intensive Care, 3(1): 16.

Horne, B.; Anderson, J.; John, J. et al., (2005): Which white blood cell subtypes predict increased cardiovascular risk? J Am Coll Cardiol, 45:1638-1643.

Ibrahim, N. and El-Kady, E. (2016): Antigenic cross-reactivity and species-specific identification of Pseudocerastes persicus fieldi snake venom. Toxicon, 119:194202.

Isbister, G.; Maduwage, K.; Scorgie, F. et al., (2015): Venom concentrations and clotting factor levels in a prospective cohort of Russell's viper bites with coagulopathy. PLoS Negl Trop Dis, 9(8): 1-12.

Isbister, G.; Gault, A.; Tasoulis, T. et al., (2016): A definite bite by the Ornamental Snake (Denisonia maculata) causing mild envenoming. Clin Toxicol (Phila), 54(3):241-244.

Kang, C.; Kim, S.; Lee, S. et al., (2013): Absolute lymphocyte count as a predictor of mortality in emergency department patients with paraquat poisoning. PLoS One, 8(10): e78160.

Kang, S.; Moon, J. and Chun B. (2016): Does the traditional snakebite severity score correctly classify envenomated patients? Clin Exp Emerg, 3(1): 34-40.

Kawahara T.; Furuya, K.; Nakamura, M. et al., (2016): Neutrophil-to-lymphocyte ratio is a prognostic marker in bladder cancer patients after radical cystectomy. BMC Cancer, 16:185.

Kaya, M.; Akpek, M.; Lam, Y. et al., (2013): Prognostic value of neutrophil/lymphocyte ratio in patients with ST-elevated myocardial infarction undergoing primary coronary intervention: a prospective, multicenter study. Int $\mathbf{J}$ Cardiol, 168:1154-1159.

Khin, M.; Nyuntb, T.; Ooc, N. et al., (2012): Prognostic indicators in patients with snakebite: analysis of two-year data from a township hospital in central Myanmar. WHO South-East Asia Journal of Public Health, 1(2):144-150.

Kiran, S. and Senthilnathan, T. (2003): Management of snake envenomation. Update in Anesthesia, 16: Article -6: 3-18.

Kokcu, A.; Kurtoglu, E.; Celik, H. et al., (2014): May the platelet to lymphocyte ratio be a prognostic factor for epithelial ovarian cancer? Asian Pac J Cancer Prev, 15:97819784.

Koseoglu, H.; Altunkas, F.; Doruk, S. et al., (2015): Platelete lymphocyte ratio is an independent predictor for cardiovascular disease in obstructive sleep apnea syndrome. J Thromb Thrombolysis, 39:179-185.

Lee, Y.; Choi, C.; Kim, H. et al., (2012): Pretreatment neutrophil:lymphocyte ratio as a prognostic factor in cervical carcinoma. Anticancer Res, 32: 1555-1561.

Maduwage, K.; O'Leary, M. and Isbister, G. (2014): Diagnosis of snake envenomation using a simple phospholipase A2 assay. Scientific Reports, 4: 4827. 
Mishal, H.; Mishal, R. and Saudagar, R. (2015): Focus on the various corridors of snake bite envenomation treatment- a review. International Journal of Current Research in Life Sciences, 4(12): 492-498.

Moreira, V.; Gutie'rrez, J.; Amaral, R. et al., (2009): Effect of Bothrops asper snake venom on the expression of cyclooxygenases and production of prostaglandins by peritoneal leukocytes in vivo, and by isolated neutrophils and macrophages in vitro. Prostaglandins Leukot Essent Fatty Acids, 80: 107-114.

Qin, B.; Ma, N.; Tang, Q. et al., (2016): Neutrophil to lymphocyte ratio (NLR) and platelet to lymphocyte ratio (PLR) were useful markers in assessment of inflammatory response and disease activity in systemic lupus erythematosus(SLE) patients. Mod Rheumatol, 26(3):372-376.

Ray, G.; Parija, B. and Kumar, L. (2011): Advances in management of snake bite. Medicine Update: 538-543.

Rifaioglu, E.; Sen, B.; Ekiz, O. et al., (2014): Neutrophil to lymphocyte ratio in Behcet's disease as a marker of disease activity. Acta Dermatovenerol Alp Panonica Adriat, 23: 65-67.

Salciccioli, J.; Marshall, D.; Pimentel, M. et al., (2015): The association between the neutrophilto-lymphocyte ratio and mortality in critical illness: an observational cohort study. Crit Care, 19:13-18.

Saravu, K.; Somavarapu, V.; Shastry, A. et al., (2012): Clinical profile, species-specific severity grading, and outcome determinants of snake envenomation: An Indian tertiary care hospital-based prospective study. Indian J Crit Care Med, 16(4): 187-192.

Sharma, R.; Katkar, G.; Sundaram, M. et al., (2015): Oxidative stressinduced methemoglobinemia is the silent killer during snakebite: a novel and strategic neutralization by melatonin. J. Pineal Res, 59:240-254.

Solak, Y.; Yilmaz, M.; Sonmez, A. et al., (2013): Neutrophil to lymphocyte ratio independently predicts cardiovascular events in patients with chronic kidney disease. Clin Exp Nephrol, 17:532540.

Stone, S.; Isbister, G.; Shahmy, S. et al., (2013): Immune response to snake envenoming and treatment with antivenom; complement activation, cytokine production and mast cell degranulation. PLoS Negl Trop Dis J, 7(7):e2326.

Sunbul, M.; Gerin, F.; Durmus, E. et al., (2014): Neutrophil to lymphocyte and platelet to lymphocyte ratio in patients with dipper versus non-dipper hypertension. Clin Exp Hypertens, 36:217-221.

Sunithaa, K.; Hemshekhara, M.; Santhosha, M. et al., (2011): Inhibition of hemorrhagic activity of viper venoms by n-acetyl cysteine: involvement of n-acetyl and thiol groups. Current Topics in Medicinal Chemistry, 11, 25892600.

Taylor, J. (1990): Statistical technique for data analysis. 2nd ed., Lewis Pub. Inc., USA, PP: 25-30.

Venkatraghavan, L.; Tan, T.; Mehta, J. et al., (2015): Neutrophil lymphocyte ratio as a predictor of 
systemic inflammation - A crosssectional study in a pre-admission setting. F1000Research, 4:123.

Walsh, S.; Cook, E.; Goulder, F. et al., (2005): Neutrophil-lymphocyte ratio as a prognostic factor in colorectal cancer. J SurgOncol, 91:181-184.

Wang, Y.; Bai, Z.; He, J. et al., (2016): Prognostic value of neutrophil-related factors in locally advanced cervical squamous cell carcinoma patients treated with cisplatin-based concurrent chemoradiotherapy. Disease Markers, Article ID 3740794, 9 pages.

Yao, Y.; Yuan, D.; Liu, H. et al., (2013): Pretreatment neutrophil to lymphocyte ratio is associated with response to therapy and prognosis of advanced non-small cell lung cancer patients treated with firstline platinum based chemotherapy. Cancer Immunol Immunother, 62: 471-479.

Zahorec, R. (2001): Ratio of neutrophil to lymphocyte counts: rapid and simple parameter of systemic inflammation and stress in critically ill. Bratisl LekListy, 102: 5-14.

Zornetta, I.; Caccin, P.; Fernandez, J. et al., (2012): Envenomations by Bothrops and Crotalus snakes induce the release of mitochondrial alarmins. PLoS Negl Trop Dis, 6(2): e1526. 


\title{
الملخص العربى المبئ \\ تقييم للأهمية التنبوئية المبكرة لنسبة النيتروفيل إلى الخلايا الليمفاويه ولنسبة التفبية

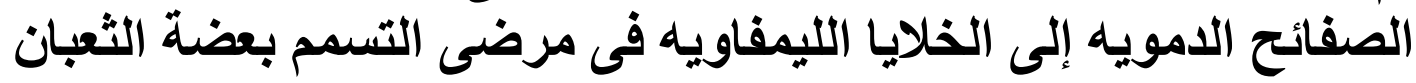

\author{
إجلال حسن العوضي 1 و هانى محمد توفيق

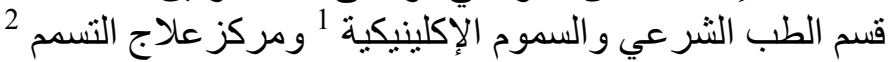 \\ كلية الطب - جامعة عين شمس الاكسة
}

نسبة النيتروفيل إلى الخلايا الليمفاويه و نسبة الصفائح الدمويه إلى الخلايا الليمفاويه حصلا مؤخراً على شهرة كدلالات إلتهاب بسيطة غير مكلفه وذات كفاءه عاليه ولقد تم اقتر احهما كمؤشر ات التهات مفيدة للتنبؤ الإكلينيكى

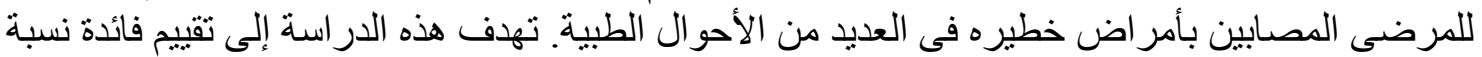
النيتروفيل إلى الخلايا الليمفاويه و نسبة الصفائح الدمويه إلى الخلايا الليمفاويه فى التنبؤ بشدة الوجهه الإكلينيكيه

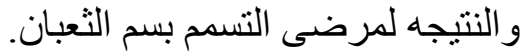
الطريقه: أجريت در اسة مستقبلية ما بين يناير و أغسطس 7 الـ ب و وأخرى استرجاعية ما بين يناير و ديسمبر

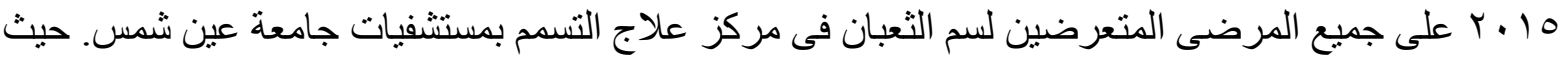

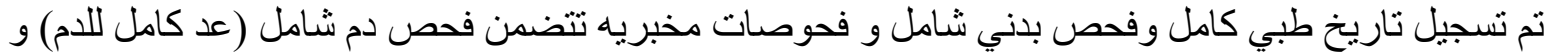

النسبة الطبيعية الدولية (آى-إن-آر)، عند الدخول. وقد تم حساب نسبة النيتروفيل إلى الخلايا الليمفاويه و نسبة فئات

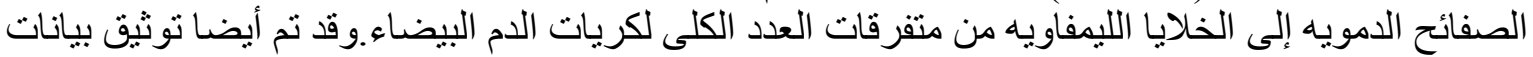

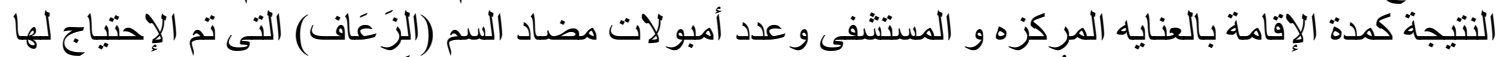

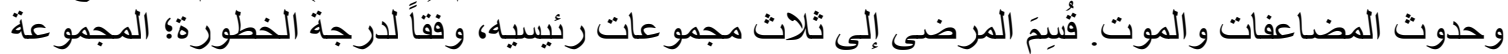
الثانية (البسيطة) و المجموعة الثالثة (المعتدلة) و المجموعة الر البعة (الثديدة). بالإضافه إلي المجمو عة الأولى

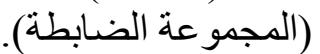

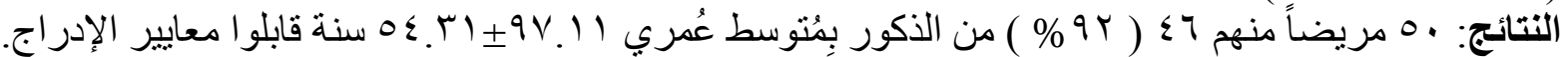

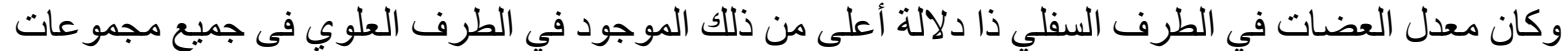

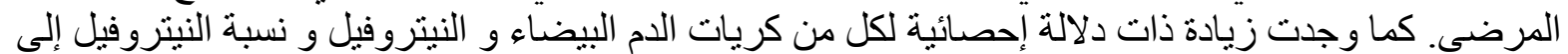

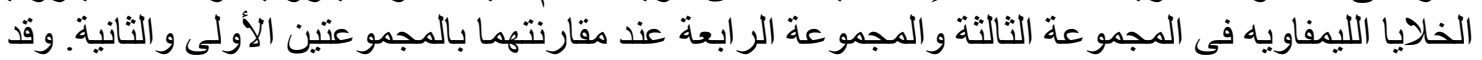

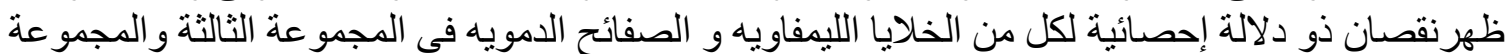

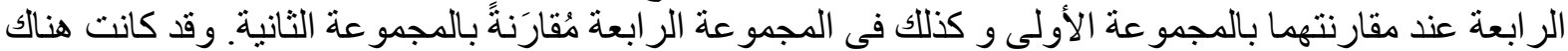

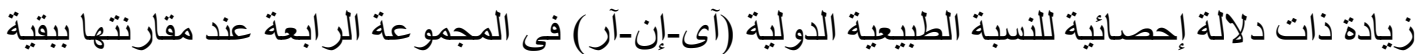

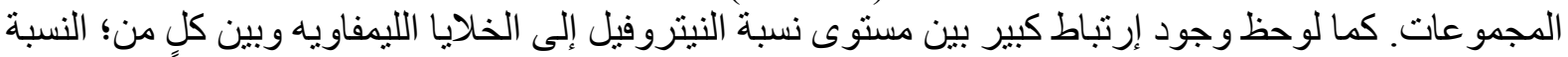

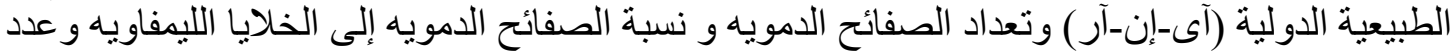

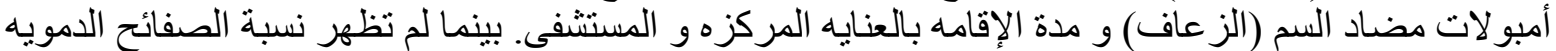

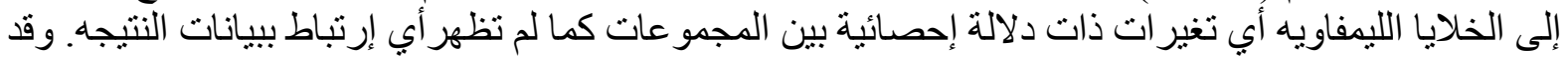

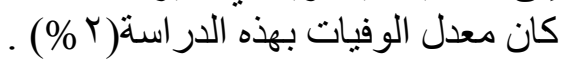

الإستتتاج: إرتفاع مستويات نسبة النيتروفيل إلى الخلايا الليمفاويه عند الدخول كان مرتبطاً بوجهه إكلينيكيه

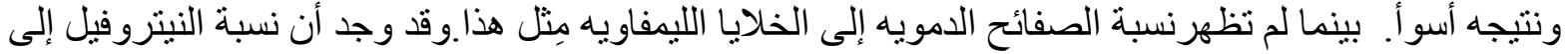

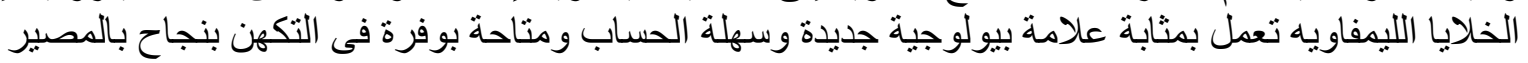

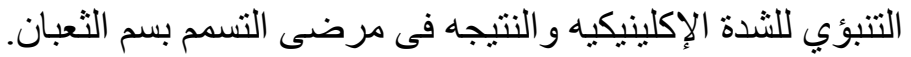

